\section{Navigating Open Science as Early Career Feminist Researchers}

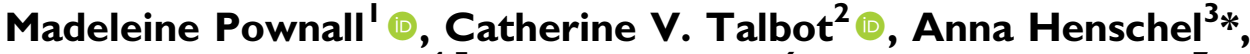 \\ Alexandra Lautarescu ${ }^{4,5}$, Kelly E. Lloyd ${ }^{6} *$, Helena Hartmann ${ }^{7} *$ (1), \\ Kohinoor M. Darda ${ }^{3,8} *$, Karen T. Y. Tang ${ }^{9 *}$, \\ Parise Carmichael-Murphy ${ }^{10} *_{(\mathbb{D})}$, and Jaclyn A. Siegel ${ }^{\prime \prime}$ (i)
}

Psychology of Women Quarterly 202I, Vol. 0(0) I-14 (C) The Author(s) 2021 (c) (1)

Article reuse guidelines: sagepub.com/journals-permissions DOI: $10.1177 / 03616843211029255$ journals.sagepub.com/home/pwq (S)SAGE

\begin{abstract}
Open science aims to improve the rigor, robustness, and reproducibility of psychological research. Despite resistance from some academics, the open science movement has been championed by some early career researchers (ECRs), who have proposed innovative new tools and methods to promote and employ open research principles. Feminist ECRs have much to contribute to this emerging way of doing research. However, they face unique barriers, which may prohibit their full engagement with the open science movement. We, 10 feminist ECRs in psychology from a diverse range of academic and personal backgrounds, explore open science through a feminist lens to consider how voice and power may be negotiated in unique ways for ECRs. Taking a critical and intersectional approach, we discuss how feminist early career research may be complemented or challenged by shifts towards open science. We also propose how ECRs can act as grass-roots changemakers within the context of academic precarity. We identify ways in which open science can benefit from feminist epistemology and end with envisaging a future for feminist ECRs who wish to engage with open science practices in their own research.
\end{abstract}

\title{
Keywords
}

open science, feminist psychology, early career researchers, open research

\section{Navigating Open Science as Early Career Feminist Researchers}

In recent years, the open science movement has prompted a discipline-wide reappraisal of the reproducibility, replicability, and robustness of psychological science (Nosek et al., 2015; Open Science Collaboration, 2015). Although uptake of open science methods throughout psychology has been relatively slow (Norris \& O'Connor, 2019), many early career researchers (ECRs) have responded to this changing landscape with enthusiasm and innovation (Bartlett \& Eaves, 2019; Farnham et al., 2017; Hobson, 2019; Orben, 2019). Here, we define open science as both the commitment to incorporating transparency in all aspects of the research process and a fundamental approach to research which aims to confront and acknowledge bias in science. Open science includes the adoption of practical tools to promote transparency, such as open sharing of data, preregistration of hypotheses prior to data collection, open peer review (i.e., reviewer transparency), and open access publishing (Munafò et al., 2017). It also includes a more ideological shift towards transparency, a questioning of dominant norms in science, and championing collaboration.
In this article, we argue that despite the plethora of scholarship that considers open science from different perspectives, there has been a notable lack of consideration for how open science may complement or indeed challenge early career work that stems from a feminist perspective. This includes open science as both a practical set of tools and a philosophical approach to doing science (Fecher \& Friesike, 2014).

There is inherent overlap between the opportunities and barriers that open science presents to academics of all research epistemologies and career stages, for example, through availability of resources to learn open science practices (Norris \& O'Connor, 2019). However, we argue that some of these barriers may be heightened for feminist ECRs, in light of (a) the longstanding marginalization of feminist research and (b) the precarious position that feminist ECRs occupy. We begin our argument by considering the unique space that all ECRs occupy in academia before then acknowledging the marginalization of feminist scholarship in mainstream spaces. We then consider the intersection between feminist and early career feminist research, noting both the barriers to participation and opportunities that open science may afford feminist ECRs. 


\section{ECRs and Open Science}

First, it is important to delineate how we are defining "early career researchers" in this context. The term "early career" in psychology generally has no clear-cut definition (Breeze \& Taylor, 2020). The British Psychological Society refers to an ECR as anyone who has completed their doctoral degree within the past 8 years, whereas the American Psychological Association ECR award criteria extend this to 10 years postdoctorate. Here, we broadly define ECRs as academics who are at the start of their career and are thus specifically affected, susceptible to, or inhibited by academic precarity (Bosanquet et al., 2017). We are also inspired by McKenzie (2017) and Murray's (2018) definitions of ECRs as younger aspiring academics, who are typically engaged in postgraduate study and aspire to be tenured, full-time academics.

Early career researchers occupy a unique position in contemporary academia, particularly given the climate of neoliberalism and precariousness (Davies \& Petersen, 2005; Tynan \& Garbett, 2007). ECRs constitute the highest proportion of researchers in higher education and they thus represent an innovative and dynamic new wave pool of global talent who has the potential to bring about disruptive change (Friesenhahn \& Beaudry, 2014; Nicholas et al., 2019). Due to a scarcity of jobs, particularly those with permanent contracts, there is an intense culture of competition and hierarchy in

\footnotetext{
'School of Psychology, University of Leeds, Leeds, UK

${ }^{2}$ Department of Psychology, Bournemouth University, Bournemouth, Dorset, UK

${ }^{3}$ Institute of Neuroscience and Psychology, University of Glasgow, Glasgow, Scotland, UK

${ }^{4}$ Forensic and Neurodevelopmental Sciences, Institute of Psychiatry, Psychology \& Neuroscience, King's College London, London, UK

${ }^{5}$ Department of Perinatal Imaging and Health, Centre for the Developing Brain, School of Biomedical Imaging and Medical Sciences, King's College London, London, UK

${ }^{6}$ Leeds Institute of Health Sciences, University of Leeds, Leeds, UK

${ }^{7}$ Social, Cognitive and Affective Neuroscience Unit, Department of Cognition, Emotion, and Methods in Psychology, Faculty of Psychology, University of Vienna, Vienna, Austria

${ }^{8}$ Department of Cognitive Sciences, Macquarie University, Sydney, Australia

${ }^{9}$ Department of Psychology and Neuroscience, Dalhousie University, Halifax, NS, Canada

${ }^{10}$ Manchester Institute of Education, The University of Manchester, Manchester, UK

"Department of Psychology, Western University, London, ON, Canada
}

*denotes equal contribution

Editor's Note: This article is part of a special issue, "Feminist Psychology and Open Science: Challenges and Opportunities," published in the Psychology of Women Quarterly. Jaclyn A. Siegel, Asia A. Eaton, Rachel M. Calogero, and Tomi-Ann Roberts served as guest editors of the special issue.

\section{Corresponding Author:}

Madeleine Pownall, School of Psychology, University of Leeds, LG.34, 4 Lifton Place, Leeds LS2 9JZ, UK.

Email: M.V.Pownall@leeds.ac.uk academia (Caretta et al., 2018). Despite this precarity, there are also "pockets of agency" that exist for ECRs (Budge, 2014, p. 69; McAlpine et al., 2014). The agency and impact of ECRs in open science spaces has been particularly notable (e.g., Nicholas et al., 2019).

Throughout open science conversations, ECRs have challenged established norms within academia and made important bottom-up changes. For example, much of the open science movement has been championed by grass-roots advocates and self-organized communities of ECRs (Orben, 2019; Pownall, 2020). In recent years, visionary ECRs have serviced the open science movement by collating reading lists (Crüwell et al., 2019), curating how-to guides (Etz et al., 2018; Kathawalla et al., 2021; Klein et al., 2018), distributing open research resources, and organizing open science conferences. The contribution that ECRs make to the advancement of knowledge and academic culture is clearly vast (Hamilton \& Pinnegar, 1998), and grass-roots bottom-up ECR-led initiatives can prompt "a cascade of sustained change" (Garvis, 2014, p. 20) in the academic discipline. Therefore, it is now useful to consider how different types of ECRs may navigate open science in unique ways.

Our Positionality. We write as a collective of 10 early career psychologists, comprising eight doctoral students, one postdoctoral researcher, and one early career lecturer. We all identify as feminist researchers and women, both of which inform the lenses through which we examine the phenomenon of open science in this article. The meaning of the term "feminist" varies slightly for each of us, depending on our unique epistemological, ontological, and methodological objectives. Feminist psychology grew out of an initiative to combat social myths and stereotypes about the roles of women in society (Shields, 1975), rapidly changing and expanding to diversify and restructure psychological science as a whole (Eagly et al., 2012). For some of us, therefore, identifying as a feminist scholar means that our research aims to shed light on the gendered experiences faced by women and girls. For others, our feminist agenda centers on reconsidering approaches to research as a whole, questioning colonial and patriarchal assumptions about the very nature of knowledge, science, and accessibility. While we differ in our research epistemology and methods, we share a fundamental concern for equity, diversity in research, and social justice. Further, as women in the collective early career stage of academia, we share a distinct set of experiences and viewpoints, which are incorporated throughout this article. Therefore, every argument, perspective, and observation in this article is directly informed by our position as feminist women ECRs. The discussion offered in the article reflects both our lived experience and shared ideological perspectives on open science, which are both aligned with a feminist viewpoint.

To understand the lived experiences of a collective, it is important to acknowledge the asymmetric power relations inherent to social dynamics (Søndergaard, 2005). This is 
aligned with Billet's (2009) notion of personal epistemologies, denoting a process through which we appreciate how our academic and professional identities intersect to shape who we are within and beyond the academy. We each adopt a personal epistemological approach here, collectively reflecting on what open science can offer to early career feminist psychologists and the potential roadblocks to participation in the movement for open science. We recognize that no struggle is a single-issue (e.g., Lorde, 1984); therefore, we do not assert that our experiences are homogenous but agree that we share a marginal position as both feminists and ECRs, while also belonging to diverse identities of race, ethnicity, age, language, sexuality, ability, and geographical location. Despite our marginalization in some academic domains, we also recognize that our affiliation and funding from universities places us in places of privilege, which provides us with the seat at the table to consider the issues outlined in this article. We refer to feminist ECRs here to include all scholars who are at the start of their academic career and broadly align themselves, either epistemologically, politically, or personally, with the goals of feminist psychology.

Feminist psychology and the psychology of women are inherently interconnected, given that feminist psychology centers reclaiming the experiences of girls and women (Fine \& Gordon, 1989). However, it is important to note that they are not entirely synonymous (Thompson, 2017). When we refer to feminist psychology or feminist research in this article, we are not necessarily referring only to women researching other women. While there are undoubtedly more women researchers who occupy feminist psychological spaces compared with men (e.g., Eagly \& Riger, 2014), here we are interested in how the experiences of researchers of any background who take a feminist perspective to their work may navigate open science in unique ways.

\section{Feminist Psychology Research as a Marginalized Area}

Feminist psychologists have prompted us to consider the questions that we ask (Rutherford, 2007) and "inquire about how we inquire" (Ackerly \& True, 2008, p. 695; Dahlberg \& Dahlberg, 2020). This is also arguably a goal of the open science movement. Advocates for open science encourage the discipline to adopt a more critical and transparent approach by reappraising current academic practices (Aspendorpf et al., 2013; Shrout \& Rodgers, 2018). Thus, the core principles of open science may be thought of as being inherently aligned with feminist values, in that the movement ultimately aims to challenge and acknowledge biases and reimagine the way that power is distributed and governed (e.g., Allen \& Mehler, 2019). These biases may include unchecked assumptions about perceptions of scientific value, researcher positionality, and determinants of research objectivity.

However, for all areas of psychology to participate equally and inclusively in open science, all areas of psychology should be considered equal to begin with (Fokken \& van Kessel, 2020). To date, the principles and practices of feminist psychology have historically been marginalized from mainstream psychology (Eagly \& Riger, 2014; MacArthur \& Shields, 2014; Rutherford et al., 2010). Research also demonstrates that the identity of a being a feminist is widely stigmatized (e.g., Houvouras \& Scott Carter, 2008; Ramsey et al., 2007). This means that the label of feminist can often be viewed as an insult (Schafer \& Shaw, 2008). Thus, identifying explicitly as a feminist early career researcher is considered to be a risk (Curtin et al., 2016). Some have suggested that this is due to the notion that feminists evoke perceptions of threat that disrupts the status quo (Cottrell \& Neuberg, 2005). There is also stigma associated with being a feminist "killjoy," a term coined by Ahmed (2010) that refers to the notion of feminists being "spoilsports" who "ruin the fun" by questioning dominant ideals and disrupting taken-for-granted norms (Murray, 2018). Therefore, feminist researchers must contend with this feminist stigma in their scholarship (Anastosopoulos \& Desmarais, 2015).

We argue that the marginalization of feminist research is particularly problematic for ECRs in this field, who have a less established sense of voice and are therefore less equipped to destabilize mainstream norms of research (Macoun \& Miller, 2014; Thwaites \& Pressland, 2017). This leads to ongoing grapples of power as conservative academics attempt to maintain the status quo and silence or minimize the efforts of younger, more critical feminist researchers (Murray, 2018). Similarly, feminist epistemology is often regarded as less scientific than other more mainstream or positivist modes of research epistemology (Wigginton \& LaFrance, 2019). Relatedly, women researchers are generally regarded to be less competent than men (e.g., in students; Moss-Racusin et al., 2012) and masculine gender-typed research topics are regarded as more scientific than topics perceived to be feminine (KnoblochWesterwick et al., 2013). This may be due to the potentially disruptive or socially transformative nature of feminist voices in psychology (Flick, 2015; Wigginton \& LaFrance, 2019) which means that feminist psychologists must fight to be heard (Wilkinson, 1996, 1997). Due to the history of silencing, coupled with the precariousness of early career positions in academia, it is imperative that open science remains sensitive to these issues and challenges encountered by feminist ECRs (Thwaites \& Pressland, 2017).

\section{Barriers to Participation in Open Science as a Feminist ECR}

While some of the emergent tools within the open science movement are useful in overcoming systemic and practical problems within academia, there are undoubtedly unique challenges that feminist ECRs face in this arena, which open science is not yet equipped to respond to. For example, a recent conference poster by Koyama and Page-Gould (2020) 
provides a useful synthesis of ECRs' concerns about implementing open science practices into their work; most notably, fear of persecution, insecurities, and social dynamics that exist within scientific publishing. Importantly, the authors also note that a barrier to participation in open science is the perception of "limited discussion about [...] whose participation is valued." This notion is echoed in the Open and Collaborative Science in Development Network's (2017) manifesto, which also calls into question whose voice is regarded as important or credible in science. Given that early career voices are often the least valued in research spheres and that feminist ideas are regularly problematized or marginalized, their attempts to contribute to open science may be regarded as trivial or unimportant (Vargo, 2017).

Similarly, feminist ECRs may also face heightened pressures when engaging in open science spaces, or indeed academia more widely (e.g., see Fokken \& van Kessel, 2020). For example, some scholars have suggested that making mistakes in open science processes, such as during the pre-registration procedure, are likely to "normalize the humanness of research" and thus improve confidence in the research process (Kathawalla et al., 2021, p. 21). However, given the precarity of the academic job market, routine mistakes and errors made through the learning process of open science may result in adverse reputational and personal consequences for feminist researchers and those in the early stages of their careers (Allen \& Mehler, 2019). It is important to note that research that stems from a feminist perspective is more readily scrutinized compared to research that fits more neatly into the "masculinist scientific culture" of methodologies (Young \& Hegarty, 2019, p. 454).

Therefore, open science as a field should respond to these concerns by working to distribute power more equally and democratize knowledge-making (Istratii \& Porter, 2018; Spates, 2012). Open science advocates should re-examine past practices to demonstrate awareness of cultural biases which reinforce unequal power structures in open science, so as not to perpetuate Eurocentric discourse and enforce the social values that (re)create power imbalances (Spates, 2012). In this context, before encouraging openness as a status quo in psychological science, we must consider what else is being opened up in the process and who governs this process (Bahlai et al., 2019). Psychological science, and open science more specifically, has been historically dominated by white, male, middle-class voices, and ideological hegemony remains a dominant component of perceived scholarly aptitude (Margolis \& Romero, 1998; Read et al., 2003). These normative practices mean that women are often excluded from mainstream conversations and thus face unique barriers to participation (Gruber et al., 2020). Given that feminist researchers are disproportionately women, this means that feminist scholars are disadvantaged in mainstream spheres. One useful framework to consider this through is Black feminist thought, which offers an epistemological framework that critiques how white, cis-gendered, heteronormative, and able-bodied discourse ascribes power to knowledge production (Alinia, 2015).

As a research community, we have yet to develop a knowledge infrastructure which truly exemplifies equality and comprehensiveness to allow for equitable participation (Okune et al., 2018). Inclusive knowledge infrastructures enable diverse agents to participate and collaborate in research processes by means of open platforms, networks, tools, and resources. Such virtual infrastructures acknowledge and readdress power relations, increase in-group collegiality, and are thus specifically beneficial to ECRs adopting a feminist stance (Gardiner, 2005; Okune et al., 2018). However, there is an underlying assumption that once open digital infrastructures become available they will be adopted worldwide or that researchers will be able to participate in the scientific process. Although online collaboration can help to dismantle the barriers to participation that ECRs in the Global South face (Iyandemye \& Thomas, 2019), issues such as technological accessibility create difficulties for women in developing countries (Gillward, 2018).

Vulnerability, Well-Being, and Invisible Labor. There are also barriers to feminist ECRs' personal well-being in open science spaces. Specifically, overwork and high levels of occupational stress result in unattainable expectations being placed on ECRs (Allmer, 2018; Pitt \& Mewburn, 2016). For some ECRs, transparency can highlight and amplify the vulnerabilities imposed by open science (Albornoz \& Chan, 2017; Pownall, 2020). For example, signed open peer review, whereby reviews are openly published together with the final article, can highlight and exacerbate power imbalances (e.g., retaliation from senior academics for critical reviews). Similarly, drives towards wider transparency of research may also leave feminist ECRs open to heightened criticism given the marginalization and stigma associated with feminist scholarship. Given that feminist psychology typically centers and celebrates vulnerability (England, 1994; Griffin, 2012), these concerns are likely enhanced in ECR work stemming from this perspective. This aligns with the broader concern of open science exacerbating power imbalances by failing to acknowledge the context and history of power relations (Albornoz \& Chan, 2017).

A further barrier to engagement with open science as a feminist ECR is a culture of increasingly abrasive and competitive online debate in open science conversations, colloquially referred to as "\#bropenscience" (e.g., Whitaker \& Guest, 2020). Bropen science demonstrates how open science spaces are typically governed by white, male, Western values and voices (e.g., see Murphy et al., 2020). As Derksen (2019) highlights, this hyper-patriarchal discourse largely disadvantages minority groups and inhibits participation (see also Rinke \& Wuttke, 2020). As Whitaker and Guest (2020) explain, not all "bros" within \#bropenscience are men; instead, bros are academics who operate with rigid thinking, a lack of self-awareness, and a tendency for hostility, unkindness, and 
exclusion. Similarly, research also demonstrates that scientific bullying is typically, but not always, directed towards women (Gruber et al., 2020). Scientific bullying, in this context, includes instances whereby a researcher alleges malpractice with the goal to damage another researcher's reputation, for example, by lobbying for retractions with unproven allegations (Lewandowsky \& Bishop, 2016). The boundary between useful and healthy academic debate and problematic scientific bullying is increasingly blurred as efforts to improve the transparency of science become more mainstream (Lewandowsky \& Bishop, 2016; Murphy et al., 2020).

Therefore, given the propensity for open science debate and discussion to be derailed by "bropen scientists" and to become a space for hostility and trolling, this creates a specific barrier for feminist ECRs. Research demonstrates how feminist discourses are similarly derailed online, for example, through backlash to feminist agency (Cole, 2015), including to feminist academics who share their work on online (e.g., Talbot \& Pownall, 2021). Feminist ECRs engaging with open science thus face the double risk of encountering both bropen scientists and anti-feminist trolls when sharing their work, which is a notable challenge in the early career stage, given how ECRs have a less established voice and sense of agency compared with more senior colleagues. With this in mind, we posit that an ideal open science environment would also include a mental health agenda, particularly given that graduate students who occupy early career status are more than six times as likely to experience anxiety and depression compared to the general population (Evans et al., 2018). These issues are particularly prevalent in marginalized groups, such as women (Levecque et al., 2017). However, open science should also work to expand the inclusivity and diversity of people who represent the movement, unraveling the \#bropenscience discourse that has previously left feminist ECRs feeling unable, or undeserving, of participation (e.g., Rinke \& Wuttke, 2020).

Further, beyond the risk of trolling, there is a vast amount of invisible labor involved in the promotion, adoption, and engagement with open science practices, with particular challenges for feminist ECRs (Social Sciences Feminist Network Research Interest Group, 2017). For example, the UK Athena SWAN Charter has been criticized for placing the burden and responsibility of gender equality upon women and other marginalized groups (Tzanakou \& Pearce, 2019). Similarly, ECRs typically contribute undervalued and under-rewarded housekeeping tasks of practices, such as science communication, contributing to open educational resources, volunteering in administration, and serving on committees (Bird et al., 2004). This issue is exacerbated when academics enter motherhood (Hunter \& Leahey, 2010; Viglione, 2020) and is also amplified by existing racial disparities of invisible labor (Roberson, 2020). More broadly, as Ledgerwood et al. (2021) also note, invisible labor in open science also includes the care work involved in mentoring other academics and the often more intensive labor that goes into producing reproducible and replicable work (e.g., checking code and cleaning data) that may easily go unrecognized. This work is largely unrewarded and often falls to ECRs and other minoritized groups (e.g., Rideau, 2019). While this labor in itself is not necessarily problematic, this poses challenges for feminist ECRs in a heightened way. For example, feminist ECRs may be likely to sacrifice their own career gains in order to help others, given (a) the marginalization of this group and (b) more notably, how an "ethics of care" governs feminist scholarship (e.g., Larrabee, 2016).

Open Science in Qualitative Early Career Research. Moreover, while there is no one distinct feminist research method (Harding, 1989) and no one methodology can be more feminist than another (Peplau \& Conrad, 1989), feminist scholars in psychology tend to use qualitative methodologies (Eagly \& Riger, 2014). This is largely due to how qualitative methodology holds unique potential to ask, address, and analyze feminist research questions (Eagly \& Riger, 2014; Gergen, 2008). Similarly, qualitative researchers are overwhelmingly women (Plowman \& Smith, 2011). However, the majority of open science practices in psychology have been developed for quantitative research. Indeed, this argument has reignited long-standing debates about the use of positivist evaluation criteria, which is concerned with objective, verifiable, and measurable phenomena, for evaluating qualitative research (Smith \& McGannon, 2018). The popularization of a positivist open science framework has direct ramifications for qualitative ECRs; if feminist psychology as a discipline is marginalized, feminist, postpositivist qualitative work in open science is likely to experience this in a heightened way.

For example, the principles of open data do not translate well to qualitative approaches due to enhanced ethical issues such as increased risk of participant identification (Chauvette et al., 2019) and challenges relating to data ownership (Branney et al., 2019). If ECRs' qualitative research does not fit within an open science framework, their career outcomes may be adversely impacted and their work regarded as less rigorous and consequently less fundable and publishable (Siegel \& LaMarre, 2019). This is particularly true for scholars whose work focuses on vulnerable populations (such as survivors of violence and women in precarious housing) who are unable to make research data available due to safety or legal concerns. Despite these challenges, if scholars continue to reimagine open science tools to suit a qualitative epistemology, more feminist ECRs will be included in this space (Branney et al., 2019; Haven \& van Grootel, 2019; Tsai et al., 2016)

Collaboration and Collegiality. Community, collegiality, and collaboration are hallmarks of the feminist agenda (Lorde, 1984). Feminist research values cross-career collaboration in the form of mentorship, support, and supervision of junior colleagues (Acker \& Wagner, 2019), as well as friendship (Kaeppel et al., 2020). Collaboration is also a cornerstone of 
open science (e.g., Open Science Collaboration, 2015), whereby rigorous and transparent science is made possible due to international and cross-disciplinary collaboration (Brock, 2020). Importantly, collaborating with diverse groups in the context of open science can dismantle the gatekeeping and exclusivity of mainstream academia (Burns et al., 2003; Fischhoff, 2013; Jucan \& Jucan, 2014), given that collaboration is so broadly defined (Dai et al., 2018; Hormia-Poutanen \& Forsström, 2016) and thus encompasses a wide range of perspectives (Nicholas et al., 2019). In this context, working collaboratively can extend the possibility of research and subsequently aid career advancement (Heffernan, 2020).

Open and collaborative science should foster unbiased and fair collaboration between scientists, enable co-creation, and make room for social innovation in society. Women's participation is less constrained in open science spaces than in other arenas of academia (Murphy et al., 2020). However, ECRs' capacity for collaboration is closely governed by supervisors and senior colleagues (Kathawalla et al., 2021) who may not (fully) endorse open science practices (Allen \& Mehler, 2019). Feminist ECR engagement in collaboration is also embedded in a context of intense competition for grants and job security (Levecque et al., 2017). This means that collaboration is often institutionally unrecognized and unrewarded (Breeze \& Taylor, 2020), and ECRs are inherently incentivized to engage in "competition rather than collaboration" (Gill \& Donaghue, 2016, p. 93). Consequently, ECRs are forced to make career choices that support this established system, thus creating a vicious cycle.

There are also benefits to well-being for ECRs who collaborate. Collaboration can buffer against competitiveness (Breeze \& Taylor, 2020), foster a healthy work environment, and offer critical political resources for feminist ECRs, especially within increasingly competitive and corporatized university environments (Macoun \& Miller, 2014). In turn, this can drastically improve ECRs' well-being. For example, Macoun and Miller (2014) reported that a collaborative feminist reading group provided ECRs with an environment of support and belonging, as well as an informal space to extend disciplinary knowledge, develop one's academic skillset, and enable the transmission of cultural and social capital. In order to embed collaboration and collegiality in open science, the movement should focus on creating accessible and usable infrastructures for all agents (Alejandra, 2018) and challenging existing claims of objectivity and universality (Okune et al., 2018).

By working collaboratively, as is often the case in open science research (Murphy et al., 2020), ECRs can resist occupying marginalized spaces which do not fit neatly within academic molds or regulations (Fitzgerald, 2014) thus allowing space to reappraise and reimagine the tensions and challenges of academia (Bassett \& Marshall, 1998). Indeed, shared experiences of inequality within academia can serve as an "emancipatory process" (Mavin \& Bryans, 2002, p. 248) by forging collaboration, togetherness, excellence, and innovation (Nielsen et al., 2018). It is the use of collaboration which has led to the creation of these ECRs' initiatives in open science.

Finally, it is important to consider open science and feminist research from multiple vantage points and perspectives. Some ECRs are further marginalized by geographical location. For example, in sharp contrast to Western practices, ECRs in the Global South face unique challenges when navigating the world of open science (Lebel \& McLean, 2018; Nobes \& Harris, 2019). In this region, data sharing is limited due to a lack of structural and systemic incentives that promote sharing (Serwadda et al., 2018). In Argentina, social movement activists prefer not to engage in data sharing due to fear of political persecution (Open Collaborative Science in Development Network, 2017). Similarly, Traynor and Foster (2017) describe how South African scientists have concerns about open knowledge sharing due to history of exploitation by European scholars. Other barriers include access to resources and availability of capital that promote open science. Moreover, barriers to publication charges may be even more pronounced in the Global South; a study on ECRs in these regions found that only $14 \%$ of the $181 \mathrm{re}-$ spondents received a publication fee waiver, whereas $60 \%$ reported they paid such fees out of pocket (Nobes \& Harris, 2019). Therefore, until open science can be fully open and accessible to researchers from all research epistemologies, career stages, and geographical locations, its impact will be notably limited.

\section{Benefits of Open Science for Feminist ECRs}

In light of these concerns about the marginalization of feminist scholarship, we suggest that open science may be a useful ally to feminist ECRs, by facilitating active and legitimate participation in academic spaces that have previously been closed off to those without access to insider knowledge (Fokken \& van Kessel, 2020; Thwaites \& Pressland, 2017). Given the "forward-looking focus" of open science, which has been suggested to give way to more collaborative and inclusive ways of doing science (Murphy et al., 2020, p. 24156), the open science movement could provide some useful practical benefits to feminist ECRs (e.g., Toribio-Flórez et al., 2021). Thus, there may be selfish reasons to engage in open science practices as a feminist ECR or as an ECR in general (Markowetz, 2015).

ECRs experience pressure to publish in prestigious journals to meet the demands of academic job criteria (Siegel \& LaMarre, 2019). Open science tools offer practical benefits for ECRs navigating this pressure. For example, open access publications, open data, code, and materials, preprints (Sarabipour et al., 2019), and registered reports are associated with increased citation rates (Hobson, 2019; Piwowar \& Vision, 2013; Pontika, 2015; Sarabipour et al., 2019) and allow more timely sharing of academic work. Many of these 
tools are considered scientific outputs with their own digital object identifiers, which can help ECRs establish their scholarly reputation, improve academic curriculum vitas, and increase employability (Aarts, 2017; Markowetz, 2015; O'Carroll et al., 2017). While these practical benefits may not be uniquely relevant to feminist ECRs (see Toribio-Flórez et al., 2021), they are particularly useful for ECRs stemming from this perspective given how feminist psychology involves the reclaiming of agency and power in mainstream spaces. In this sense, we suggest that open science tools may allow feminist ECRs to compete equally, such as by removing the barriers to disseminating research outputs despite the negative perceptions of the research area and the marginalization of ECRs as a group.

The practical benefits of open science for feminist ECRs are also likely to grow, as funders, journals, and stakeholders begin to exert top-down pressure for implementing open science practices. This is evidenced in initiatives such as Coalition S and Plan S (Schiltz, 2018), the Leiden Manifesto (Hicks et al., 2015), TOP guidelines (Nosek et al., 2017), and UK Reproducibility Network (Munafò et al., 2020). Similarly, several universities now include evidence of open research practices in their hiring and promotion criteria (e.g., Bristol, Glasgow, Cardiff, Berlin Charite University Hospital, Montreal Neurological Institute, and Ghent University; Kowalczyk et al., 2020). Thus, there are notable competitive advantages in engaging in open science practices for ECRs (e.g., Kathawalla et al., 2021). Moreover, open research as a criterion in hiring and promotion will increase the competitive advantage that feminist ECRs who adopt open science practices have over those who do not (Kowalczyk et al., 2020). This can make a vital difference for feminist ECRs, particularly for those from traditionally marginalized and under-represented groups in academia, by ensuring that the work involved in this research is highlighted and appropriately credited. In essence, open science may allow feminist ECRs to further the reach and accessibility of their research, which can have practical benefits for ECRs as they grapple with establishing a scholarly reputation (e.g., Aarts, 2017; Markowetz, 2015; O’Carroll et al., 2017).

Moreover, there are some instances where ECRs stemming from a feminist epistemology are afforded unique benefits, for example, in light of the open science calls to "slow down" science. Many open science advocates have argued for the benefits of slow science, citing this as a mechanism to improve the robustness and rigor of psychological research (Frith, 2020; Siegel \& LaMarre, 2019). Most early career work is typically time-sensitive and highly pressured which makes it incompatible with these calls to slow down science (Yon, 2021). However, the work that feminist ECRs do may be more readily compatible with these shifts. In parallel to the open science conversations, Mountz et al. (2015) call explicitly for a slowing down of feminist scholarship, arguing that "publish or perish" cultures are inherently at odds with a feminist commitment to incorporate a feminist ethics of care, self- compassion, and thoughtfulness into the research process. This is echoed by Hartman and Darab (2012) who note that the marketization of neoliberal academia does not allow sufficient time and space to think and instead is overly consumed with the pressures to produce. The authors note that this academic culture is in direct contradiction with a feminist approach to scholarship. Therefore, this is a unique instance whereby the goals of open science advocates and feminist scholarship are well aligned, which may mean that feminist ECRs can more readily participate.

Open Science as an Ally to Women. Finally, given that feminist research is intrinsically concerned with gender equality and that the majority of feminist scholars are women (Eagly et al., 2012), open science practices may also buffer against some of the gendered inequalities present in academia. For example, open access publishing may mitigate the gender citation advantage, whereby men receive more citations (Aksnes et al., 2011; Odic \& Wojcik, 2020). Moreover, improper credit allocation can exacerbate existing power imbalances in academia (Street et al., 2010; Van den Eynden et al., 2016). Women are less likely than men to be senior authors on scholarly publications (Odic \& Wojcik, 2020) and ECRs report experiences of others taking credit for their work. Novel open research initiatives such as the Contributor Roles Taxonomy, which specifies different roles involved in a research project and openly assigns them to each author (CRediT; Allen et al., 2019), can empower feminist ECRs to transparently take proper credit for their work and obtain appropriate and deserved recognition (Schmidt et al., 2018). Therefore, attempts at leveling the playing field through open science culture shifts (Munafò et al., 2017) are particularly useful for ECRs who may not have access to the inside knowledge (or the "hidden curriculum") of academia (Reay, 2004).

\section{Reimagining Open Science for Feminist ECRs}

Given that open science is an emergent movement within psychological science and beyond, there is scope to reimagine and redefine its aims and goals in a way that represents the concerns discussed throughout this article (see also Ledgerwood et al., 2021, for a recent reimagining of open science). Therefore, it is useful to consider what open science, particularly one that responds to the barriers and benefits to feminist ECRs, could look like. In essence, a reimagined open science that benefits feminist ECRs should respond sensitively to the concerns raised throughout this discussion. It should champion all early career voices in an equitable and inclusive way, acknowledge the systemic marginalization that feminist ECRs face and dismantle hierarchies that pervade academia. This can begin by expanding the use of core open science tools that are at ECRs' current disposal, such as more transparent ways of publishing (e.g., Registered reports, preprints, and open access articles) and innovative ways of fostering 
collaboration (e.g., MultiLab Collaborations and Open Science Framework). While concrete empirical research on how feminist ECRs navigate open science spaces is still lacking, we strongly hope that this article can serve as a basis for future investigations and inspire ECRs engaging in open science to rethink their values and practices.

As well as systemic change, there are some take-home messages that may be useful for fellow feminist ECRs, and indeed ECRs more generally, as they navigate the world of open science. For example, it is important to note that an all-ornothing approach to open science is not the only way to participate (Bowman \& Keene, 2018; Klein et al., 2018). Starting out in open science can be daunting for many ECRs as there are multiple options and resources available, but it is important to start in a way that feels most comfortable and accessible, while accounting for the inherent precarity and lack of agency that ECRs assume in academia. Ideally, open science should not be static, but rather a flexible learning process that adapts to its users. However, we also acknowledge that engagement in open science can often require a substantial level of inside knowledge, connections, and resources. These resources can be both physical or economical (e.g., access to funding and equipment) as well as pastoral or related to personal care (e.g., receiving adequate support from supervisors or senior academics). There are unique cultural, social, and personal reasons that may create barriers to participation in open science, which often requires concessions at these early career stages. Therefore, an open science that is truly open and accessible to all should readily confront the various barriers and challenges that we have highlighted throughout this article.

Due to these barriers, ECRs are often reluctant to implement open science practices for fear of it impacting negatively upon their career progression, although this is not a universal experience. Despite these challenges, ECRs can be powerful open science changemakers, demonstrating a voice which can empower others and lead meaningful, long-lasting change in psychological science and beyond. As academia begins to embrace open research, we anticipate more ECRs becoming the voice of change in their respective departments, research groups, or even institutions and promoting open science for future generations of scientists. To further promote inclusive and accessible open science ECRs should consider whose story is centered in their research and who is credited for this knowledge production (Dyer \& Ivens, 2020). Ideally, a future of open science would encourage scholars to indicate in their methodology sections where, why, and how knowledge is produced during the research (Allen \& Mehler, 2019; Dyer \& Ivens, 2020). A more inclusive open science should also recognize that there may be legitimate cases when it is not appropriate or possible to participate fully in open science practices, such as in the instances of publicly sharing data. Therefore, advocates for the open science movement should aim to accommodate a more flexible and accessible approach to these kinds of research practices, fully acknowledging the diversity and complexity of researchers' capacity to engage.
It may also be useful to contextualize this discussion and recommendations against growing claims that there is an ideological bias in psychology that favors liberal left-wing views which are typically championed by feminist epistemologies (Jussim et al., 2015). It is important that efforts to include feminist researchers into the open science community do not inadvertently replace one kind of ideological bias with another. Rigorous and theoretically robust science should ideally champion ideological and epistemological diversity (Harper, 2020). Therefore, while we demonstrate how one kind of ideology may be negotiated in unique ways in the context of open science, efforts to support ideological diversity in a nonhostile way that does not silence or marginalize should also be more widely considered. For example, more nuanced embedding of ideological perspectives into psychological science may be achieved via adversarial collaborations, in which members of contrasting ideological standpoints work together in collaboration (e.g., Cowan et al., 2020; Nier \& Campbell, 2013). Ultimately, the future of open science should work to be more accommodating to alternative perspectives.

\section{Conclusion}

Together, feminism and open science can collectively challenge the historical domination of Western-centric and heteropatriarchal approaches to knowledge. Researchers should not adopt a one-size-fits-all approach to open science (Hillyer et al., 2017). Instead, they should aim to be more inclusive of different approaches to science, including those that stem from feminist epistemology. There have been efforts to adapt open science practices to alternative research methodologies (Haven \& van Grootel, 2019; Kern \& Gleditsch, 2017; Tsai et al., 2016); however, as feminist ECRs occupy a precarious and marginal position, their voices should be centered in the development of emergent open science tools. Currently, the literature which directly addresses how feminist or critical epistemologies may not be wholly compatible with open science is in its infancy. Open science should further welcome marginalized communities to unpack what the open science movement means for them so that ECRs know how not to be complicit with the silencing, devaluing, or marginalizing of others.

\section{Author Contributions}

Conceptualization: Madeleine Pownall, Catherine V. Talbot, Anna Henschel, Alexandra Lautarescu, Kelly E. Lloyd, and Jaclyn Siegel. Project Administration: Madeleine Pownall, Catherine V. Talbot, and Jaclyn Siegel. Supervision: Madeleine Pownall, Catherine V. Talbot, and Jaclyn Siegel. Writing - Original Draft Preparation: Madeleine Pownall, Catherine V. Talbot, Anna Henschel, Alexandra Lautarescu, Kelly E. Lloyd, Helena Hartmann, Kohinoor M. Darda, Karen T. Y. Tang, Parise Carmichael-Murphy, and Jaclyn Siegel. WritingReview \& Editing: Madeleine Pownall, Catherine V. Talbot, Anna Henschel, Alexandra Lautarescu, Kelly E. Lloyd, Helena Hartmann, Kohinoor M. Darda, Karen T. Y.Tang, Parise Carmichael-Murphy, and Jaclyn Siegel (Allen et al., 2019). 


\section{Declaration of Conflicting Interests}

The author(s) declared no potential conflicts of interest with respect to the research, authorship, and/or publication of this article.

\section{Funding}

The author(s) disclosed receipt of the following financial support for the research, authorship, and/or publication of this article: MP is supported by a doctoral scholarship from the University of Leeds, School of Psychology. CVT is supported by the Faculty of Science \& Technology, Bournemouth University. AH is supported by the European Research Council (ERC) under the European Union's Horizon 2020 research and innovation programme (Grant agreement number 677270 to Emily S. Cross). AL is supported by the UK Medical Research Council (MR/N013700) and King's College London member of the MRC Doctoral Training Partnership in Biomedical Sciences. KEL is supported by the Economic and Social Research Council (ES/P000745/1). HH is supported by the uni:docs scholarship of the University of Vienna, the Austrian Science Fund (FWF W1262-B29) and the Vienna Science and Technology Fund (WWTF VRG13-007). KMD is supported by the Leverhulme Trust (Grant PLP-2018-152 to Emily S. Cross). KTYT is supported by the Canadian Institutes of Health Research (CIHR). PCM is supported by the National Lottery Community Fund.

\section{Citation Diversity Statement}

In this article, we sought to proactively select references that reflect the diversity of the field in form of contribution, gender, race, and ethnicity (Zurn et al., 2020). To check for this, we obtained the predicted gender of the first and last author of each reference by using databases that store the probability of a first name being carried by a woman. By this measure (and excluding self-citations to the first and last authors of our current article), our references contain $54.22 \%$ woman (first)/woman (last), $13.25 \% \mathrm{man} /$ woman, $12.05 \%$ woman $/ \mathrm{man}$, and $20.48 \% \mathrm{man} / \mathrm{man}$. This method is limited in that (a) names, pronouns, and social media profiles used to construct the databases may not, in every case, be indicative of gender identity and (b) it cannot account for intersex, non-binary, or transgender people. We look forward to future work that could help us to better understand how to support equitable practices in science.

\section{ORCID iDs}

Madeleine Pownall (D) https://orcid.org/0000-0002-3734-8006 Catherine V. Talbot (D) https://orcid.org/0000-0001-9353-8990 Helena Hartmann (D) https://orcid.org/0000-0002-1331-6683

Parise Carmichael-Murphy (D) https://orcid.org/0000-0002-20639827

Jaclyn A. Siegel (D) https://orcid.org/0000-0003-0620-2597

\section{References}

Aarts, A. A. (2017). Open practices badges for curricula vitae: An additional way to help change incentives in psychological science? PsyArXiv. doi:10.31234/osf.io/n5rdv

Ackerly, B., \& True, J. (2008). Reflexivity in practice: Power and ethics in feminist research on international relations. International
Studies Review, 10(4), 693-707. doi:10.1111/j.1468-2486.2008. 00826.x

Acker, S., \& Wagner, A. (2019). Feminist scholars working around the neoliberal university. Gender and Education, 31(1), 62-81. doi:10.1080/09540253.2017.1296117

Ahmed, S. (2010). Killing joy: Feminism and the history of happiness. Signs: Journal of Women in Culture and Society, 35(3), 571-594. doi:10.1086/648513

Aksnes, D. W., Rorstad, K., Piro, F., \& Sivertsen, G. (2011). Are female researchers less cited? A large-scale study of Norwegian scientists. Journal of the American Society for Information Science and Technology, 62(4), 628-636. doi:10.1002/asi.21486

Albornoz, D., \& Chan, L. (2017). Power and inequality in open science discourses. Open Science Conference, 1(4), 70-79. https://periodicos.ufpe.br/revistas/IRIS/article/viewFile/ $238912 / 30639$

Alejandra, D. (2018, December 26). Reimagining open science through a feminist lens. Open and collaborative science in development network. https://medium.com/@denalbz/reimaginingopen-science-through-a-feminist-lens-546f3d10fa65

Alinia, M. (2015). On black feminist thought: Thinking oppression and resistance through intersectional paradigm. Ethnic and Racial Studies, 38(13), 2334-2340. doi:10.1080/01419870. 2015.1058492

Allen, C., \& Mehler, D. M. (2019). Open science challenges, benefits and tips in early career and beyond. Plos Biology, 17(5), 1-14 doi:10.1371/journal.pbio.3000246

Allen, L., O’Connell, A., \& Kiermer, V. (2019). How can we ensure visibility and diversity in research contributions? How the contributor role taxonomy (CRediT) is helping the shift from authorship to contributorship. Learned Publishing, 32(1), 71-74. doi:10.1002/leap.1210

Allmer, T. (2018). Precarious, always-on and flexible: A case study of academics as information workers. European Journal of Communication, 33(4), 381-395. doi:10.1177/0267323118783794

Anastosopoulos, V., \& Desmarais, S. (2015). By name or by deed? Identifying the source of the feminist stigma. Journal of Applied Social Psychology, 45(4), 226-242. doi:10.1111/jasp.12290

Aspendorpf, J. B., Conner, M., De Fruyt, F., De Houwer, J., Denissen, J. J., Fiedler, K., Fiedler, S., Funder, D. C., Kliegl, R., Nosek, B. A., Perugini, M., Roberts, B. W., Schmitt, M., van Aken, M. A. G., Weber, H., \& Wicherts, J. M. (2013). Recommendations for increasing replicability in psychology. European Journal of Personality, 27(2), 108-119. doi:10.1002/per.1919

Bahlai, C., Bartlett, L., Burgio, K., Fournier, A., Keiser, C., Poisot, T., \& Whitney, K. (2019). Open science isn't always open to all scientists. American Scientist, 107(2), 78-82. doi:10.1511/2019. 107.2.78

Bartlett, J., \& Eaves, J. (2019). Getting to grips with open science. In H. Walton (Ed.), Guide for psychology postgraduates: Surviving postgraduate study (2nd ed., pp. 85-89). British Psychological Society.

Bassett, P., \& Marshall, H. (1998). Women working as casual academics: A marginalized group. Journal of Management \& Organization, 4(2), 10-17. doi:10.5172/jmo.1998.4.2.10 
Billet, S. (2009). Personal epistemologies, work and learning. Educational Research Review, 4(3), 210-219. doi:10.1016/j. edurev.2009.06.001

Bird, S., Litt, J. S., \& Wang, Y. (2004). Creating status of women reports: Institutional housekeeping as 'women's work'. NWSA Journal, 16(1), 194-206. https://www.jstor.org/stable/4317042

Bosanquet, A., Mailey, A., Matthews, K. E., \& Lodge, J. M. (2017). Redefining 'early career' in academia: A collective narrative approach. Higher Education Research \& Development, 36(5), 890-902. doi:10.1080/07294360.2016.1263934

Bowman, N. D., \& Keene, J. R. (2018). A layered framework for considering open science practices. Communication Research Reports, 35(4), 363-372. doi:10.1080/08824096.2018.1513273

Branney, P., Reid, K., Frost, N., Coan, S., Mathieson, A., \& Woolhouse, M. (2019). A context-consent meta-framework for designing open (qualitative) data studies, Qualitative Research in Psychology, 16(3), 483-502, doi:10.1080/14780887.2019. 1605477

Breeze, M., \& Taylor, Y. (2020). Feminist collaborations in higher education: Stretched across career stages. Gender and Education, 32(3), 412-428, doi:10.1080/09540253.2018.1471197

Brock, J. (2020). Massive collaboration. The Psychologist, 33, 24-29. https://thepsychologist.bps.org.uk/volume-33/october-2020/ massive-collaboration

Budge, K. (2014). Finding pockets of agency. In N. Lemon \& S. Garvis (Eds.), Being "in and out": Providing voice to early career women in academia (pp. 69-78). Springer. doi:10.1007/ 978-94-6209-830-5_7

Burns, T. W., O’Connor, D. J., \& Stocklmayer, S. M. (2003). Science communication: A contemporary definition. Public Understanding of Science, 12(2), 183-202. doi:10.1177/09636625030122004

Caretta, M. A., Drozdzewski, D., Jokinen, J. C., \& Falconer, E. (2018). "Who can play this game?" The lived experiences of doctoral candidates and early career women in the neoliberal university. Journal of Geography in Higher Education, 42(2), 261-275. doi:10.1080/03098265.2018.1434762

Chauvette, A., Schick-Makaroff, K., \& Molzahn, A. E. (2019). Open data in qualitative research. International Journal of Qualitative Methods, 18, 1-6. doi:10.1177/1609406918823863

Cole, K. K. (2015). "It's like she's eager to be verbally abused": Twitter, trolls, and (en) gendering disciplinary rhetoric. Feminist Media Studies, 15(2), 356-358. doi:10.1080/14680777.2015. 1008750

Cottrell, C. A., \& Neuberg, S. L. (2005). Different emotional reactions to different groups: A sociofunctional threat-based approach to prejudice. Journal of Personality and Social Psychology, 88(5), 770-789 doi:10.1037/0022-3514.88.5.770

Cowan, N., Belletier, C., Doherty, J. M., Jaroslawska, A. J., Rhodes, S., Forsberg, A., Naveh-Benjamin, M., Barrouillet, P., Camos, V., \& Logie, R. H. (2020). How do scientific views change? Notes from an extended adversarial collaboration. Perspectives on Psychological Science, 15(4), 1011-1025. doi:10.1177/ 1745691620906415

Crüwell, S., van Doorn, J., Etz, A., Makel, M. C., Moshontz, H., Niebaum, J. C., Orben, A., Parsons, S., \& Schulte-Mecklenbeck,
M. (2019). Seven easy steps to open science. Zeitschrift für Psychologie, 227(4), 237-248. doi:10.1027/2151-2604/ a000387

Curtin, N., Ramsey, L. R., \& Tran, J. (2016). The benefits and risks of feminist practice as early career scholars in social psychology. In T. A. Roberts, N. Curtin, L. E. Duncan, \& L. M. Cortina. (Eds.) Feminist perspectives on building a better psychological science of gender (pp. 353-379). Springer. doi:10.1007/978-3-31932141-7_20

Dahlberg, H., \& Dahlberg, K. (2020). Phenomenology of science and the art of radical questioning. Qualitative Inquiry, 26(7), 889-896. doi:10.1177/1077800419897702

Dai, Q., Shin, E., \& Smith, C. (2018). Open and inclusive collaboration in science: A framework. OECD science, Technology and industry working articles. OECD Publishing, Paris. doi:10. 1787/2dbff737-en

Davies, B., \& Petersen, E. B. (2005). Neoliberal discourse in the academy. The forestalling of (collective) resistance. Learning and Teaching in the Social Sciences, 2(2), 32-54. doi:10.1386/ ltss.2.2.77/1

Derksen, M. (2019, September 19-20). The tone debate: How to be critical in science. Replication of crises: Psychology in times of epistemic upheaval workshop. Lübeck. https://pure.rug.nl/ws/ portalfiles/portal/97877124/paper.pdf.

Dyer, S., \& Ivens, G. (2020). What would a feminist open source investigation look like? Digital War, 1, 1-33. doi:10.1057/ s42984-020-00008-9

Eagly, A. H., Eaton, A., Rose, S. M., Riger, S., \& McHugh, M. C. (2012). Feminism and psychology: Analysis of a half-century of research on women and gender. American Psychologist, 67(3), 211-230. doi:10.1037/a0027260

Eagly, A. H., \& Riger, S. (2014). Feminism and psychology: Critiques of methods and epistemology. American Psychologist, 69(7), 685-702. doi:10.1037/a0037372

England, K. V. L. (1994). Getting personal: Reflexivity, positionality, and feminist research. The Professional Geographer, 46(1), 80-89. doi:10.1111/j.0033-0124.1994.00080.x

Etz, A., Gronau, Q. F., Dablander, F., Edelsbrunner, P. A., \& Baribault, B. (2018). How to become a Bayesian in eight easy steps: An annotated reading list. Psychonomic Bulletin \& Review, 25(1), 219-234. doi:10.3758/s13423-017-1317-5

Evans, T. M., Bira, L., Gastelum, J. B., Weiss, L. T., \& Vanderford, N. L. (2018). Evidence for a mental health crisis in graduate education. Nature Biotechnology, 36(3), 282-284. doi:10.1038/ nbt.4089

Farnham, A, Kurz, C, Öztürk, MA, Solbiati, M, Myllyntaus, O, Meekes, J, Pham, TM, Paz, C, Langiewicz, M, Andrews, S, Kanninen, L, Agbemabiese, C, Guler, AT, Durieux, J, Jasim, S, Viessmann, O, Frattini, S, Yembergenova, D, \& ... Benito, CM, Porte, M, Grangeray-Vilmint, A, Curiel, RP, Rehncrona, C, Malas, T, Esposito, F, Hettne, K 2017). Early career researchers want open science. Genome Biology, 18(1), 221-224. doi:10. 1186/s13059-017-1351-7

Fecher, B., \& Friesike, S. (2014). Open science: One term, five schools of thought. In S. Bartling \& S. Friesike (Eds.), 
Opening science (pp. 17-47). Springer. doi:10.1007/978-3319-00026-8 2

Fine, M., \& Gordon, S. M. (1989). Feminist transformations of/ despite psychology. In M. Crawford \& M. Gentry (Eds.), Gender and thought: Psychological perspectives (pp. 146-174). Springer. doi:10.1007/978-1-4612-3588-0_8

Fischhoff, B. (2013). The sciences of science communication. Proceedings of the National Academy of Sciences, 110(3), 14033-14039. doi:10.1073/pnas. 1213273110

Fitzgerald, T. (2014). Being "in and out": Providing voice to early career women in academia. In N. Lemon \& S. Garvis (Eds.), Being "in and out": Providing voice to early career women in academia (pp. 10-12). Springer.

Flick, U. (2015). Qualitative research as social transformation. In M. Murray (Ed.), Critical health psychology (pp. 182-199). Macmillan. doi:10.1007/978-1-137-28267-5 11

Fokken, M., \& van Kessel, L. (2020). Gender and open science/ scholarship. Tijdschrift Voor Gender Studies, 23(2), 103-111. doi:10.5117/TVGN2020.2.001.FOKK

Friesenhahn, I., \& Beaudry, C. (2014). The global state of young scientists: Project report and recommendations. Akademie Verlag. https://globalyoungacademy.net/wp-content/uploads/ 2015/06/GYA_GloSYS-report_webversion.pdf.

Frith, U.. (2020). Fast lane to slow science. Trends in Cognitive Sciences, 24(1), 1-2. doi:10.1016/j.tics.2019.10.007

Gardiner, J. K. (2005). On collegiality, collectivity and gender. Symplokē, 13(12), 108-120. https://www.jstor.org/stable/40550620

Garvis, S. (2014). Are you old enough to be in academia? You don't have grey hair: Constructions of women in academia. In N. Lemon \& S. Garvis (Eds.), Being "in and out": Providing voice to early career women in academia (pp. 19-30). Springer.

Gergen, M. (2008). Qualitative methods in feminist psychology. In C. Willig \& W. Stainton Rogers (Eds.), The SAGE handbook of qualitative research in psychology (pp. 280-295). Sage.

Gill, R., \& Donaghue, N. (2016). Resilience, apps and reluctant individualism: Technologies of self in the neoliberal academy. Women's Studies International Forum 54, 91-99. doi:10.1016/j. wsif.2015.06.016

Gillward, A. (2018, November 2). Understanding the gender gap in the Global South. World Economic Forum. https://www. weforum.org/agenda/2018/11/understanding-the-gender-gapin-the-global-south/

Griffin, G. (2012). The compromised researcher: Issues in feminist research methodologies. Sociologisk Forskning, 49(4) 333-347. https://www.jstor.org/stable/24393263

Gruber, J., Mendle, J., Lindquist, K. A., Schmader, T., Clark, L. A., Bliss-Moreau, E., Akinola, M., Atlas, L., Barch, D. M., Barrett, L. F., Borelli, J. L., Brannon, T. N., Bunge, S. A., Campos, B., Cantlon, J., Carter, R., Carter-Sowell, A. R., Chen, S., Craske, M. G., \& ... Williams, L. A. (2020). The future of women in psychological science. Group Processes \& Intergroup Relations, 20(5), 606-620. doi:10.1177/1368430217712052

Hamilton, M. L., \& Pinnegar, S. (1998). Conclusion: The value and promise of self-study. In M. L. Hamilton (Ed.) Reconceptualizing teaching practice: Developing competence through self-study (pp. 235-246). Routledge.

Harding, S. (1989). Is there a feminist method? In N. Tuana (Ed.), Feminism and science (pp. 18-32). Indiana University Press

Harper, C. A. (2020, March 19). Ideological measurement in social and political psychology. PsyArXiv. doi:10.31234/osf.io/wpsje.

Hartman, Y., \& Darab, S. (2012). A call for slow scholarship: A case study on the intensification of academic life and its implications for pedagogy. Review of Education, Pedagogy, and Cultural Studies, 34(1-2), 49-60. doi:10.1080/10714413.2012.643740

Haven, T. L., \& van Grootel, D. L. (2019). Preregistering qualitative research. Accountability in Research, 26(3), 229-244. doi:10. 1080/08989621.2019.1580147

Heffernan, T. (2020, September 21). The importance of networks for career advancement in academia. EduResearch Matters. https:// www.aare.edu.au/blog/?p=7507

Hicks, D., Wouters, P., Waltman, L., De Rijcke, S., \& Rafols, I. (2015). Bibliometrics: The Leiden Manifesto for research metrics. Nature, 520(7548), 429-431. doi:10.1038/520429a

Hillyer, R., Posada, A., Albornoz, D., Chan, L., \& Okune, A. (2017). Framing a situated and inclusive open science: Emerging lessons from the open and collaborative science in development network. In L. Chan \& F. Loizides (Eds.), Expanding perspectives on open science: Communities, cultures and diversity in concepts and practices (pp. 18-33). IOS Press.

Hobson, H.. (2019). Registered reports are an ally to early career researchers. Nature Human Behavior, 3, 1010. doi:10.1038/ s41562-019-0701-8

Hormia-Poutanen, K., \& Forsström, P.-L. (2016). Collaboration at international, national and -institutional level - vital in fostering open science. LIBER Quarterly, 26(1), 3-12. doi:10.18352/lq. 10157

Houvouras, S., \& Scott Carter, J. (2008). The F word: College students' definitions of a feminist. Sociological Forum, 23(2), 234-256. doi:10.1111/j.1573-7861.2008.00072.x

Hunter, L. A., \& Leahey, E. (2010). Parenting and research productivity: New evidence and methods. Social Studies of Science, 40(3), 433-451. doi:10.1177/0306312709358472

Istratii, R., \& Porter, H. (2018). Understanding the possibilities and limitations of open access publishing for decolonising knowledge-making and dissemination. The SOAS Journal of Postgraduate Research, 11(2017-2018), 185-194. doi:10. 25501/SOAS.00026319

Iyandemye, J., \& Thomas, M. P. (2019). Low income countries have the highest percentages of open access publication: A systematic computational analysis of the biomedical literature. Plos One, 14(7), e0220229. doi:10.1371/journal.pone.0220229

Jucan, M. S., \& Jucan, C. N. (2014). The power of science communication. Procedia - Social and Behavioral Sciences, 149, 461-466. doi:10.1016/j.sbspro.2014.08.288

Jussim, L., Crawford, J. T., Anglin, S. M., \& Stevens, S. T. (2015). Ideological bias in social psychological research. In J. Forgas, K. Fiedler, \& W. Crano (Eds.), Social psychology and politics (pp. 91-109). Routledge. 
Kaeppel, K., Grenier, R. S., \& Björngard-Basayne, E. (2020). The F Word: The role of women's friendships in navigating the gendered workplace of academia. Human Resource Development Review, 19(4), 362-383. doi:10.1177/1534484320962256

Kathawalla, U.-K., Silverstein, P., \& Syed, M. (2021). Easing into open science: A guide for graduate students and their advisors. Collabra: Psychology, 7(1), 18684. doi:10.1525/collabra.18684

Kern, F. G., \& Gleditsch, K. S. (2017). Exploring pre-registration and pre-analysis plans for qualitative inference. ResearchGate. doi: 10.13140/RG.2.2.14428.69769.

Klein, O., Hardwicke, T. E., Aust, F., Breuer, J., Danielsson, H., Hofelich Mohr, A., Ijzerman, H., Nilsonne, G., Vanpaemel, W., \& Frank, M. C. (2018). A practical guide for transparency in psychological science. Collabra: Psychology, 4(1), 20. doi:10. 1525/collabra. 158

Knobloch-Westerwick, S., Glynn, C. J., \& Huge, M. (2013). The Matilda effect in science communication: An experiment on gender bias in publication quality perceptions and collaboration interest. Science Communication, 35(5), 603-625. doi:10.1177/ 1075547012472684

Kowalczyk, O., Lautarescu, A., Blok, E., Dall'Aglio, L., \& Westwood, S. J. (2020). What senior academics can do to support reproducible and open research: A short, three-step guide. PsyArXiv. doi:10.31234/osf.io/jyfr7.

Koyama, J., \& Page-Gould, E. (2020, March 18). The open science conversation. [Poster presentation]. Open Science Framework. osf.io/7mqud

Larrabee, M. J. (Ed.). (2016). An ethic of care: Feminist and interdisciplinary perspectives. Routledge.

Lebel, J., \& McLean, R. (2018, July 4). A better measure of research from the global south. Nature. doi:10.1038/d41586018-05581-4.

Ledgerwood, A., Hudson, S. T. J., Lewis, N. A., Jr., Maddox, K. B., Pickett, C., Remedios, J. D., \& ... Wilkins, C. L. (2021). The pandemic as a portal: reimagining psychological science as truly open and inclusive. PsyArXiv. doi:10.31234/osf.io/gdzue.

Levecque, K., Anseel, F., De Beuckelaer, A., Van der Heyden, J., \& Gisle, L. (2017). Work organization and mental health problems in PhD students. Research Policy, 46(4), 868-879. doi:10.1016/ j.respol.2017.02.008

Lewandowsky, S., \& Bishop, D. (2016). Research integrity: Don't let transparency damage science. Nature, 529(7587), 459-461. https://www.nature.com/news/research-integrity-don-t-lettransparency-damage-science-1.19219

Lorde, A. (1984). Sister outsider: Essays and speeches by Audre Lorde. Crossing Press.

MacArthur, H. J., \& Shields, S. A. (2014). Psychology's feminist voices: A critical pedagogical tool. Sex Roles, 70(9-10), 431-433. doi:10.1007/s11199-014-0349-9

Macoun, A., \& Miller, D. (2014). Surviving (thriving) in academia: Feminist support networks and women ECRs. Journal of Gender Studies, 23(3), 287-301. doi:10.1080/09589236.2014. 909718

Margolis, E., \& Romero, M. (1998). The department is very male, very white, very old, and very conservative“: The functioning of the hidden curriculum in graduate sociology departments. Harvard Educational Review, 68(1), 1-33. doi:10.17763/haer. 68.1.1q3828348783j851

Markowetz, F. (2015). Five selfish reasons to work reproducibly. Genome Biology, 16(1), 1-4. doi:10.1186/s13059-015-0850-7

Mavin, S., \& Bryans, P. (2002). Academic women in the UK: Mainstreaming our experiences and networking for action. Gender and Education, 14(3), 235-250. doi:10.1080/ 0954025022000010703

McAlpine, L., Amundsen, C., \& Turner, G. (2014). Identity-trajectory: Reframing early career academic experience. British Educational Research Journal, 40(6), 952-969. doi:10.1002/ berj. 3123

McKenzie, L. (2017). A precarious passion: Gendered and age-based insecurity among aspiring academics in Australia. In R. Thwaites \& A. Pressland (Eds.), Being an early career feminist academic: Global perspectives, experiences, and challenges (pp. 31-49). Palgrave Macmillan.

Moss-Racusin, C. A., Dovidio, J. F., Brescoll, V. L., Graham, M. J., \& Handelsman, J. (2012). Science faculty's subtle gender biases favor male students. Proceedings of the National Academy of Sciences, 109(41), 16474-16479. doi:10.1073/ pnas. 1211286109

Mountz, A., Bonds, A., Mansfield, B., Loyd., J, Hyndman, J., Walton-Roberts, M., Basu, R., Whitson, R., Hawkins, R., Hamilton, T., \& Curran, W. (2015). For slow scholarship: A feminist politics of resistance through collective action in the neoliberal university. ACME: An International Journal for Critical Geographies, 14(4), 1235- 1259. https://acme-journal. org/index.php/acme/article/view/1058

Munafò, M. R., Chambers, C. D., Collins, A. M., Fortunato, L., \& Macleod, M. R. (2020). Research culture and reproducibility. Trends in Cognitive Sciences, 24(2), 91-93. doi:10.1016/j.tics. 2019.12.002

Munafò, M. R, Nosek, B. A, Bishop, D. V. M, Button, K. S, Chambers, C. D, Du Sert, N. P, Simonsohn, U, Wagenmakers, E. J, Ware, J. J, \& Ioannidis, J. P. A (2017). A manifesto for reproducible science. Nature Human Behaviour, 1(1), 0021-0029. doi:10.1038/s41562016-0021

Murphy, M. C., Mejia, A. F., Mejia, J., Yan, X., Cheryan, S., Dasgupta, N., Destin, M., Fryberg, S. A., Garcia, J. A., Haines, E. L., Marackiewicz, J. M., Ledgerwood, A., Moss-Racusin, C. A., Park, L. E., Perry, S. P., Ratliff, K. A., Rattan, A., Sanchez, D. T., Savani, K., \& ... Pestilli, F. (2020). Open science, communal culture, and women's participation in the movement to improve science. Proceedings of the National Academy of Sciences of the United States of America, 117(39), 24154-24164. doi:10.1073/pnas.1921320117.

Murray, Ó. M. (2018). Feel the fear and killjoy anyway: Being a challenging feminist presence in precarious academia. In Y. Taylor \& K. Lahar (Eds.) Feeling academic in the neoliberal university (pp. 163-189). Palgrave Macmillan.

Nicholas, D., Watkinson, A., Boukacem-Zeghmouri, C., RodríguezBravo, B., Xu, J., Abrizah, A., Swigon, M., Clark, D., \& Herman, E. (2019). So, are early career researchers the 
harbingers of change? Learned Publishing, 32(3), 237-247. doi: 10.1002/leap. 1232

Nielsen, M. W., Bloch, C. W., \& Schiebinger, L. (2018). Making gender diversity work for scientific discovery and innovation. Nature Human Behaviour, 2(10), 726-734. doi:10.1038/ s41562-018-0433-1

Nier, J. A., \& Campbell, S. D. (2013). Two outsiders' view on feminism and evolutionary psychology: An opportune time for adversarial collaboration. Sex Roles, 69(9-10), 503-506. doi:10. 1007/s11199-012-0154-2

Nobes, A., \& Harris, S. (2019). Open Access in low- and middleincome countries: Attitudes and experiences of researchers. [Preprint ahead of publication]. Emerald Open Research, 1, 17. doi:10.35241/emeraldopenres.13325.1

Norris, E., \& O'Connor, D. B. (2019). Science as behaviour: Using a behaviour change approach to increase uptake of open science. Psychology \& Health, 34(12), 1397- 1406, doi:10.1080/ 08870446.2019.1679373

Nosek, B. A., Alter, G., Banks, G. C., Borsboom, D., Bowman, S., Breckler, S., Buck, S., Chambers, C., Chin, G., Christensen, G., Contestabile, M., Dafoe, A., Eich, E., Freese, J., \& DeHaven, A. (2017). Transparency and openness promotion (TOP) guidelines. Open Science Framework. https://osf.io/9f6gx/

Nosek, B. A., Alter, G., Banks, G. C., Borsboom, D., Bowman, S. D., Breckler, S. J., Buck, S., Chambers, C. D., Chin, G., Christensen, G., Contestabile, M., Dafoe, A., Eich, E., Freese, J., Glennerster, R., Goroff, D., Green, D. P., Hesse, B., Humphreys, M., \& ... Yarkoni, T. 2015). Promoting an open research culture. Science, 348(6242), 1422-1425. doi:10.1126/science.aab2374

O'Carroll, C., Rentier, B., Cabello Valdès, C., Esposito, F., Kaunismaa, E., Maas, K., Metcalfe, J., McAllister, D., Vandevelde, K., \& Lossau, N. (2017, November 14). Evaluation of research careers fully acknowledging open science practices-rewards, incentives and/or recognition for researchers practicing open science. Publication Office of the European Union. doi:10.2777/ 75255.

Odic, D., \& Wojcik, E. H. (2020). The publication gender gap in psychology. American Psychologist, 75(1), 92-103. doi:10. 1037/amp0000480

Okune, A., Hillyer, R., Albornoz, D., Posada, A., \& Chan, L. (2018). Whose infrastructure? Towards inclusive and collaborative knowledge infrastructures in open science. [Conference presentation] ELPUB 2018. doi:10.4000/proceedings.elpub.2018.31.

Open Collaborative Science in Development Network. (2017). Open science manifesto. OCSDNet. https:/ocsdnet.org/manifesto/ open-science-manifesto/

Open Science Collaboration. (2015). Estimating the reproducibility of psychological science. Science, 349(6251), aac4716. doi:10. 1126/science.aac4716

Orben, A. (2019). A journal club to fix science. Nature. doi:10.1038/ d41586-019-02842-8.

Peplau, L. A., \& Conrad, E. (1989). Beyond nonsexist research: The perils of feminist methods in psychology. Psychology of Women Quarterly, 13(4), 379-400. doi:10.1111/j.1471-6402.1989. tb01009.x
Pitt, R., \& Mewburn, I. (2016). Academic superheroes? A critical analysis of academic job descriptions. Journal of Higher Education Policy and Management, 38(1), 88-101. doi:10.1080/ 1360080X.2015.1126896

Piwowar, H. A., \& Vision, T. J. (2013). Data reuse and the open data citation advantage. PeerJ, 1, e175. doi:10.7717/peerj.175

Plowman, D. A., \& Smith, A. D. (2011). The gendering of organisational research methods: Evidence of gender patterns in qualitative research. Qualitative Research in Organizations and Management: An International Journal, 6(1), 64-82. doi:10. 1108/17465641111129399

Pontika, N. (2015). Open Access: What's in it for me as an early career researcher? Journal of Science Communication, 14(4), 1-12 doi:10.22323/2.14040304

Pownall, M. (2020, June 1). Early career researchers in open science: Vanguard or cannon fodder? The Psychologist. https:// thepsychologist.bps.org.uk/early-career-researchers-openscience-vanguard-or-cannon-fodder

Ramsey, L. R., Haines, M. E., Hurt, M. M., Nelson, J. A., Turner, D. L., Liss, M., \& Erchull, M. J. (2007). Thinking of others: Feminist identification and the perception of others' beliefs. Sex Roles, 56(9-10), 611-616. https://10.1007/s11199-007-9205-5

Read, B., Archer, L., \& Leathwood, C. (2003). Challenging cultures? Student conceptions of 'belonging' and 'isolation' at a post1992 university. Studies in Higher Education, 28(3), 261-277. doi:10.1080/03075070309290

Reay, D. (2004). Cultural capitalists and academic habitus: Classed and gendered labour in UK higher education. Women's Studies International Forum 27(1), 31-39. doi:10.1016/j.wsif.2003.12.006

Rideau, R. (2019). "We're just not acknowledged": An examination of the identity taxation of full-time non-tenure-track Women of Color faculty members. Journal of Diversity in Higher Education. Advance online publication. doi:10.1037/dhe0000139.

Rinke, E. M., \& Wuttke, A. (2020). Open minds, open methods: Transparency and inclusion in pursuit of better scholarship. PS: Political Science \& Politics, 54(2), 281-284. doi:10.1017/ S1049096520001729

Roberson, M. L. (2020). On supporting early-career Black scholars. Nature Human Behaviour, 4(8), 773. doi:10.1038/s41562-0200926-6

Rutherford, A. (2007). V. feminist questions, feminist answers: Towards a redefinition. Feminism \& Psychology, 17, 459-464. doi: $10.1177 / 0959353507084327$

Rutherford, A., Vaughn-Blount, K., \& Ball, L. C. (2010). Responsible opposition, disruptive voices: Science, social change, and the history of feminist psychology. Psychology of Women Quarterly, 34(4), 460-473. doi:10.1111/j.1471-6402.2010. 01596.x

Sarabipour, S., Debat, H. J., Emmott, E., Burgess, S. J., Schwessinger, B., \& Hensel, Z. (2019). On the value of preprints: An early career researcher perspective. PLOS Biology 17(2): e3000151. doi:10.1371/journal.pbio.3000151

Schafer, C. E., \& Shaw, G. M. (2008). The polls - trends: Tolerance in the United States. Public Opinion Quarterly, 37(2), 404-431. doi:10.1093/poq/nfp022 
Schiltz, M. (2018). Science without publication paywalls: Coalition S for the realisation of full and immediate open access. PLoS Medicine, 15(9), e1002663. doi:10.1371/journal.pmed.1002663

Schmidt, B, Ross-Hellauer, T, van Edig, X, \& Moylan, EC (2018). Ten considerations for open peer review. F1000Research, 7(969). doi:10.12688/f1000research.15334.1

Serwadda, D., Ndebele, P., Grabowski, M. K., Bajunirwe, F., \& Wanyenze, R. K. (2018). Open data sharing and the Global South-Who benefits? Science, 359(6376), 642-643. doi:10. 1126/science.aap8395

Shields, S. (1975). Functionalism, darwinism, and the psychology of women. American Psychologist, 30(7), 739-754. doi:10.1037/ h0076948

Shrout, P. E., \& Rodgers, J. L. (2018). Psychology, science, and knowledge construction: Broadening perspectives from the replication crisis. Annual Review of Psychology, 69, 487-510. doi:10.1146/annurev-psych-122216-011845

Siegel, J. A., \& LaMarre, A. (2019). Navigating "publish or perish" as qualitative researchers. Nature behavioural and social sciences. https://socialsciences.nature.com/posts/54648-navigatingpublish-or-perish-as-qualitative-researchers

Smith, B., \& McGannon, K. R. (2018). Developing rigor in qualitative research: problems and opportunities within sport and exercise psychology. International Review of Sport and Exercise Psychology, 11(1), 101-121. doi:10.1080/1750984X.2017. 1317357

Social Sciences Feminist Network Research Interest Group. (2017). The burden of invisible work in academia: Social inequalities and time use in five university departments. Journal of Social Relations, 39, 228-245. https://www.jstor.org/stable/90007882

Søndergaard, D. M. (2005). Academic desire trajectories: Retooling the concepts of subject, desire and biography. European Journal of Women's Studies, 12(3), 297-313. doi:10.1177/ 1350506805054270

Spates, K. (2012). "The missing link": The exclusion of Black women in psychological research and the implications for Black women's mental health. Sage Open, 2(2), 1-9. doi:10.1177/ 2158244012455179

Street, J. M., Rogers, W. A., Israel, M., \& Braunack-Mayer, A. J. (2010). Credit where credit is due? Regulation, research integrity and the attribution of authorship in the health sciences. Social Science \& Medicine, 70(9), 1458-1465. doi:10.1016/j. socscimed.2010.01.013

Talbot, C. V., \& Pownall, M. (2021). "If your institution refuses to provide what you need, create it yourself": Feminist praxis on \#AcademicTwitter. Feminism and Psychology. doi:10.31234/ osf.io/v547p.

Thompson, L. (2017). Mainstreaming 'Women' without feminisms in psychology. Social and Personality Psychology Compass, 11(11), e12359. doi:10.1111/spc3.12359

Thwaites, R., \& Pressland, A. (Eds.). (2017). Being an early career feminist academic: Global perspectives, experiences and challenges. Springer.

Toribio-Flórez, D., Anneser, L., de Oliveira-Lopes, F. N., Pallandt, M., Tunn, I., \& Windel, H. (2021). Where do early career researchers stand on open science practices? A survey within the Max Planck Society. Frontiers in Research Metrics and Analytics. doi:10.3389/frma.2020.586992.

Traynor, C., \& Foster, L. (2017, October 7). Principles and practice in open science: Addressing power and inequality through 'situated openness'. Natural Justice.org https://naturaljustice. org/principles-practice-open-science-addressing-power-inequalitysituated-openness/

Tsai, A. C., Kohrt, B. A., Matthews, L. T., Betancourt, T. S., Lee, J. K., Papachristos, A. V., Weiser, S. D., \& Dworkin, S. L. (2016). Promises and pitfalls of data sharing in qualitative research. Social Science \& Medicine, 169, 191-198. doi:10.1016/j. socscimed.2016.08.004

Tynan, B. R., \& Garbett, D. L. (2007). Negotiating the university research culture: Collaborative voices of new academics. Higher Education Research \& Development, 26(4), 411-424. doi:10. 1080/07294360701658617

Tzanakou, C., \& Pearce, R. (2019). Moderate feminism within or against the neoliberal university? The example of Athena SWAN. Gender, Work \& Organization, 26(8), 1191-1211. doi: 10.1111/gwao.12336

Van den Eynden, V., Knight, G., Vlad, A., Radler, B., Tenopir, C., Leon, D., Manista, F., Whitworth, J., \& Corti, L. (2016). Survey of Wellcome researchers and their attitudes to open research. Wellcome Trust. doi:10.6084/m9.figshare.4055448.v1.

Vargo, E. J. (2017, October 9). A manifesto for early career researchers. Times Higher Education. https://www.timeshighereducation.com/ blog/manifesto-early-career-researchers

Viglione, G.. (2020). Are women publishing less during the pandemic? Here's what the data say. Nature, 581, 365-366. doi:10. 1038/d41586-020-01294-9

Whitaker, T., \& Whitaker, B. (2020). \#bropenscience is broken science. The Psychologist, 33, 34-38. https://thepsychologist. bps.org.uk/volume-33/november-2020/bropenscience-brokenscience

Wigginton, B., \& LaFrance, M. N. (2019). Learning critical feminist research: A brief introduction to feminist epistemologies and methodologies. Feminism \& Psychology, 1-17. doi:10.1177/ 0959353519866058

Wilkinson, S. (Ed.) (1996). Feminist social psychologies: International perspectives. Open University Press.

Wilkinson, S. (1997). Feminist psychology. In D. Fox \& I. Prilleltensky (Eds.), Critical psychology: An introduction (pp. 247-264). Sage. doi:10.4135/9781446279199.n12.

Yon, D. (2021). Valuing early career psychologists. The Psychologist, 34, 40-42. https://thepsychologist.bps.org.uk/volume-34/february2021/valuing-early-career-psychologists

Young, J. L., \& Hegarty, P. (2019). Reasonable men: Sexual harassment and norms of conduct in social psychology. Feminism \& Psychology, 29(4), 453-474. doi:10.1177/ 0959353519855746

Zurn, P., Bassett, D. S., \& Rust, N. C. (2020). The citation diversity statement: A practice of transparency, a way of life. Trends in Cognitive Sciences, 24(9), 669-672. doi:10.1016/j.tics.2020.06. 009 